\title{
ESTEREOTIPOS DE GÉNERO Y DENOMINACIÓN DE PERSONAJES EN LA LETRA DE LAS CANCIONES TRADICIONALES
}

\author{
$M^{a}$ Belén Hidalgo Márquez \\ CEIP Aurora Moreno \\ mbhm35@hotmail.com
}

Recibido: 04-02-2010

Aceptado: 08-04-2010

\section{Resumen:}

Desde siempre, la música ha estado estrechamente unida a la sociedad en la que se encontraba inmersa. Su vinculación con una cultura determinada, ha ocasionado que esté influenciada por las características sociales, económicas, políticas... de un determinado momento. Precisamente, es en la letra de las canciones tradicionales, transmitidas oralmente, dónde podemos encontrar los rasgos más característicos de una forma concreta de "ver el mundo". Con este artículo queremos describir la manera en la que los personajes de las canciones aparecen en el texto de las mismas, mostrando así las diferencias a la hora de nombrarlos dependiendo de su sexo.

Palabras clave: Canciones, estereotipos de género, denominación de personajes.

\begin{abstract}
:
Traditionally, music has been closely linked to the society in which it was immersed. Its association with a particular culture has caused it to be influenced by the social, economic, political features... of a particular time. It is precisely in the lyrics of traditional songs, handed down orally, where we can find the most characteristic features of a particular form of "seeing the world". In this article we describe the
\end{abstract}


manner in which the characters of the songs appear in their lyrics, thus showing the differences at the time of naming them depending on gender.

Key words: Songs, gender stereotypes, naming of characters.

\section{Introducción}

Desde siempre, la música ha estado estrechamente unida a la sociedad en la que se encontraba inmersa y por tanto sumergida en una cultura concreta, un modo de vida, una manera de ser y de sentir del pueblo en el que nos situamos. Precisamente es esa cultura la que dicta la forma de "construir" y sentir la música, plasmando en ella creencias, costumbres, gustos...

Al estar vinculada a una cultura concreta, la música ha estado influenciada por las características sociales, económicas, políticas, culturales y religiosas de un determinado momento. De hecho no tenemos noticias de la existencia de alguna cultura sin ningún tipo de música. Así pues, cada época y cada situación histórica propone determinadas formulaciones comunes que son recogidas por los códigos de las distintas artes y manifestaciones culturales.

En cada etapa histórica se vive una realidad diferente, distintos intereses, problemas, gustos, costumbres, fiestas, ritos,... y todos ellos se manifiestan en la música, que se transmite de generación en generación en el pensamiento y la forma de vida de las personas.

Precisamente, es en la letra de las canciones tradicionales, transmitidas oralmente, dónde podemos encontrar rasgos de la forma de "ver el mundo", pensamientos, costumbres... de una época concreta. Con este artículo queremos describir la manera en la que los personajes de las canciones aparecen en el texto de las mismas, mostrando así las diferencias a la hora de nombrarlos dependiendo de su sexo. 


\section{Método}

\subsection{Objetivos}

- Comprobar la denominación de los personajes que aparecen en el texto de las canciones folclóricas.

- Proporcionar unas pautas de análisis que faciliten una mirada crítica sobre las canciones.

- Fomentar una actitud favorable y positiva ante la no discriminación.

\subsection{Muestra}

Para la realización de esta investigación, se ha tomado como punto de referencia el Cancionero infantil de la provincia de Huelva, realizado por Francisco José García Gallardo y Herminia Arredondo Pérez (1995), investigadores y docentes de la Facultad de Ciencias de la Educación.

Se ha elegido este cancionero por dos motivos. El primero por su autora y autor, porque son docentes. El segundo porque es el cancionero del contexto dónde se realiza la investigación y por tanto, el alumnado canta las canciones que están recogidas en él, pues las aprenden con sus familias, además de trabajar con ellas en las clases de música.

Las canciones aparecen clasificadas en catorce grupos según los juegos con los que han sido interpretadas: Canciones de corro y cuerda, Canciones para jugar en hileras, Canciones para jugar a la cuerda, Canciones de palmas, Canciones de elástico, Canciones de sortear y echar a suertes, Burlas, Canciones de columpio, Prendas, Pelota, Nanas y canciones de mecer, Canciones para jugar con niños pequeños, Canciones con otros juegos, Canciones interpretadas sin juego. Para el análisis de los personajes, se ha seleccionado la letra de setenta y cinco canciones. 


\subsection{Métodos de investigación}

Esta investigación se encuadra dentro de lo que se denomina etnografía descriptiva (Taylor y Bogdan, 1985). La etnografía constituye un método de investigación útil en la identificación, análisis y solución de múltiples problemas de la educación. Su objeto de estudio es la educación de las personas, vista y analizada como proceso, con una concepción holística, en la que se puede estudiar a quienes intervienen en el proceso educativo, al contexto educativo, al propio proceso o algunos de los componentes que lo integran.

\subsubsection{Análisis de contenido}

Se define el análisis de contenido como:

"[...] una técnica de investigación que identifica y describe de una manera objetiva y sistemática las propiedades lingüísticas de un texto con la finalidad de obtener conclusiones sobre las propiedades no-lingüísticas de las personas y los agregados sociales En este sentido, el «texto» puede ser tanto un escrito como un «discurso» oral (y registrado, por ejemplo, en una cinta magnetofónica). Sin embargo, en un sentido más amplio, el análisis de contenido se puede aplicar también a materiales que no sean puramente lingüísticos; por ejemplo, películas o anuncios publicitarios" Mayntz et al (1980: 198).

\subsubsection{Etapas}

A partir de autores como Mayntz R., Holm, K, y Hübner, P. (1980); LópezAranguren (1986); Bardin (1986); L Écuyer (1990); Mayer y Quellet (1991), se pueden identificar como etapas técnicas generales del análisis de contenido las siguientes:

1. El análisis previo o la lectura de documentos.

2. La preparación del material.

3. La selección de la unidad de análisis. 
4. La explotación de los resultados (análisis cuantitativo y/o análisis cualitativo).

\section{Resultados}

En las letras de las canciones, podemos apreciar que aparecen distintos personajes. Se ha considerado que un personaje es aquella persona de la cual se habla en cualquier narración. En general, puede aparecer tanto como un sustantivo o un pronombre, indicando qué tipo de sujeto se trata, pero hay ocasiones en los que se utiliza el masculino genérico para designar a varias personas de ambos géneros, lo cual dificulta, en muchas ocasiones, conocer el sexo de dichos personajes.

Así, podemos encontrar distintos personajes según sean mujeres u hombres, si son anónimos o si para denominarlos se utiliza un nombre propio, si se usa el masculino genérico o palabras con un significado neutral que se refieren a un colectivo (palabras que tienen una única forma gramatical en la que incluyen tanto a ambos sexos).

Para estudiar esta cuestión, hemos realizado un cuadro comparativo (tabla 1), en el que aparecen el $n^{\circ}$ total de personajes que surgen (tanto hombres, mujeres como palabras que se refieren a personas indeterminadas o indefinidas, ya que no se conoce su sexo), y cuántas personas son las protagonistas y los narradores/as de las canciones estudiadas. Así pues, también se ha incluido cuántas palabras aparecen en masculino genérico, utilizándose éste como válido para referirse a los dos sexos, y cuántas cuya forma gramatical incluye tanto a hombres como mujeres. 
Tabla 1: Distribución de los personajes

\begin{tabular}{|c|c|c|c|}
\hline & $\mathbf{N}^{\mathbf{0}}$ Total & Protagonistas & Narrador/a \\
\hline Hombres & 64 & 18 & 14 \\
\hline Mujeres & 86 & 37 & 18 \\
\hline Indeterminados & 60 & 17 & 43 \\
\hline Genérico masculino & 10 & 0 & 0 \\
\hline Genérico & 0 & 0 & 0 \\
\hline
\end{tabular}

Fuente: elaboración propia

Se han identificado y analizado 150 personajes en el discurso, correspondientes al texto de las canciones estudiadas, de los cuales 64 son hombres (42.66\%) y 86 mujeres (56.33\%). Como se puede apreciar, aparecen más personajes femeninos que masculinos en dicha selección de canciones.

En cuanto a la aparición de los personajes, se puede decir que las mujeres están representadas en más ocasiones como protagonistas principales de las canciones, unas 37 veces $(59.67 \%)$, mientras que los hombres unas 18 (29.03\%). Existen 17 ocasiones $(27.41 \%)$ en los que las y los protagonistas de las canciones son personajes indeterminados, pues no se especifica su sexo.

Las mujeres aparecen en todas las categorías en más ocasiones que los hombres, excepto en la de ser narradoras, pues, aunque salen más veces que los hombres, 18 veces $(24 \%)$ versus 14 de los hombres (18.66\%), son personajes indeterminados los que tienen más relevancia a la hora de realizar dicha acción en el discurso, en 43 ocasiones (57.33\%). Este hecho se debe al menosprecio sufrido por las mujeres desde hace siglos a la hora de tener un papel de relevancia en cualquier ámbito.

Para demostrar aún más cómo están repartidos los personajes en las canciones mostramos la tabla 2, en la que se representa dicha distribución. 
Tabla 2: Distribución de personajes masculinos y femeninos

\begin{tabular}{|c|c|c|}
\hline & Frecuencias & Porcentajes \\
\hline Hombres anónimos & 49 & $76.56 \%$ \\
\hline Hombres con nombre propio & 15 & $23.43 \%$ \\
\hline Total & 64 & $100 \%$ \\
\hline Mujeres anónimas & 66 & $76.74 \%$ \\
\hline Mujeres con nombre propio & 20 & $23.25 \%$ \\
\hline Total & 86 & $100 \%$ \\
\hline
\end{tabular}

Fuente: elaboración propia

En la tabla anterior, podemos apreciar cómo, aun habiendo más personajes femeninos que masculinos en los textos, las mujeres y hombres aparecen de forma similar, ya sea con nombre propio o anónimos.

Según esto, es más fácil que las chicas se sientan identificadas con el discurso empleado en las canciones y se vean reflejadas como posibles protagonistas de las acciones emprendidas, pues aparecen con mayor frecuencia en el $\mathrm{n}^{\mathrm{o}}$ total de personajes, en las protagonistas y narradoras. Pero realmente no es así, pues, como veremos en toda nuestra exposición, el prototipo de mujer que se representa en las canciones, es una mujer que nada tiene que ver con muchas féminas de hoy en día.

A parte de esto, encontramos en el texto de las canciones, la utilización del genérico masculino para referirse a ambos sexos. Esto podemos verlo en el siguiente ejemplo transcrito:

“Vamos los dos, los dos, los dos...” (Canción: Al jardín de la alegría). Se emplea este término para referirse a un hombre y una mujer, esta frase es bastante empleada en otros discursos de las canciones seleccionadas:

“Que me han dicho los toreros, que el toro me va a matar..." (Canción: Mi abuelo tiene un peral). Se utiliza la palabra "toreros" para referirse a las y los toreros: 
"Viva la media naranja, viva la naranja entera, vivan los guarida-civiles, que van por la carretera...” (Canción: Viva la media naranja). En esa frase, se emplea guardia-civiles para denominar a dicha profesión.

A nivel general, podemos afirmar, que existe un predominio de nombres propios femeninos en detrimento de los masculinos, esto es debido al aumento de las féminas en las canciones. Así pues, encontramos nombres propios de mujer como:

Catalina: “Levántate Catalina, levántate Catalina...” (Canción: a la baranda del cielo); Marisa: "La pobre de Marisa qué triste está...” (Canción: La pobre de Marisa), Isabelita: Calla, calla Isabelita, calla, calla Isabel..." (Canción: Soldado, soldadito).

Mientras que por ejemplo en los hombres podemos encontrar:

Eduardo: "La casaremos con Eduardo, materilerilerile..." (Canción: dónde están las llaves);

Pepito Zanahoria: “Y aqui termina la historia de Pepito Zanahoria..." (Canción: Han puesto una librería).

Otra forma de restar importancia a las personas en las narraciones, es utilizando diminutivos a la hora de referirse a ellas. En las canciones populares se emplea ese tipo de terminología para representar tanto a hombres como a mujeres.

A la hora de denominar a los personajes que aparecen en las canciones estudiadas, en algunas ocasiones se utiliza su nombre en diminutivo. En el análisis realizado se observa que existen más palabras en diminutivo referidas al sexo masculino que al femenino cuando se trata de su nombre de pila.

A continuación se muestran ejemplos en los que se emplean diminutivos para referirse a mujeres, haciendo referencia a su nombre de pila: 
“Calla, calla, Isabelita...” (Canción: Soldado, soldadito);

"Pepita quería ser enfermera la primera..." (Canción Pepito quería ser...).

Mientras que a la hora de hablar de los hombres, se emplean diminutivos como:

"Y aqui termina la historia de Pepito Zanahoria..." (Canción; Han puesto una librería);

"Será mi Manolito que fue a la guerra y no volvió más..." (Canción allá arribita en aquella montaña);

"Pepito en un barco me manda un papel..." (Canción: Pepito en un barco);

“Pepito quería ser capitán de un barco inglés...” (Canción: Pepito quería ser);

"Manolito huevo frito, tortilla de bacalao, que tu novia no te quiere porque estás medio chiflao" (Canción: Manolito huevo frito);

"Yo soy Pedrito, Pedrito, Pedrito..." (Canción: yo soy Yolanda).

En cuanto al estado civil de las personas, como una característica definitoria, podemos destacar una palabra que se utiliza en diminutivo para representar a las mujeres, en este caso nos referimos al término "viudita", que al masculino "viudito", es más, no se emplea dicho vocablo en ninguna de las canciones. Así podemos distinguirlo en los siguientes ejemplos:

"Arroz con leche, me quiero casar, con una viudita que está en ese portal..." (Canción: El corro de la encina);

"Yo soy la viudita del Conde Laurel, que quiero casarme y no se con quién..." (Canción: Quién dirá Carbonerita).

Si fijamos nuestra atención en las relaciones que existen entre personas de distintos sexos, a parte de viudita, se utiliza con igual frecuencia los vocablos "mamá-madre/padre", "novio/novia", "hija/hijo", "esposa/marido". El único término que no aparece en ambos sexos es el de "abuelo", como se puede comprobar en el siguiente ejemplo: 
"Mi abuelo tiene un peral, un peral de peras finas..." (Canción: Mi abuelo tiene un peral).

Se emplean palabras en señal de respeto o cortesía, cuya ubicación es anterior al nombre para referirse a mujeres y hombres. Dichas palabras se utilizan de forma de diferente si nos referimos al género masculino o femenino pues para los hombres se utiliza "Don", como se puede distinguir en el siguiente ejemplo:

“Don Federico mató a su mujer, la hizo picadillo y la echó a la sartén..." (Canción: Don Federico);

"Señor": "Al corro de la patata, comeremos ensalada, lo que comen los señores..." (Canción: Al corro de la patata);

“Estando un señor don gato, sentadito en su tejado..." (Canción: Estando un señor don gato).

Estos términos empleados, se refieren a personas con un cierto estatus social, ya que son palabras que, como hemos dicho antes, se usan en señal de respeto, mientras que para las mujeres, se utilizan adjetivos que muestran la delicadeza de las mismas, como por ejemplo:

"Señora": "Ha venido mi señora ¿cuántos hijos tiene usted?” (Canción: La hoja, hoja verde);

"Dama”: "Hay una dama sentada, sí, sí, hay una dama sentada...” (Canción: A la baranda del cielo);

“La bella dama perdió su abanico para casarse con Don Federico..." (Canción: Don Federico);

"Señorita": "La señorita Rafaela matarilerilerile, la señorita Rafaela..." (Canción: dónde están las llaves);

“La señorita Pepa ha salido al baile...” (Canción: Ha salido el sol). 
Además de los términos anteriormente comentados, en muchas ocasiones, se utilizan metáforas para referirse a las mujeres, comparando alguna parte de su cuerpo con algún objeto. Este hecho repercute en ellas, pues las muestra como "mujeres florero", es decir, personas que sirven de ornamento, cuyo aspecto es tierno y se identifican como "algo", pues son objetos cuya obligación es acompañar a un hombre. Los términos a los cuales nos referimos son los siguientes:

“Vente conmigo, rosa temprana, clavel del amor..." (Canción: Al pasar por Sevilla);

"Cogeré a Dominga por ser la más bella, de blanca azucena de mayo y abril" (Canción: Quién dirá la Carbonerita);

"Pues cojo a María por ser la más bella, y blanca azucena de este jardín" (Canción: Yo soy la viudita);

“A esta me la llevo por guapa y hermosa, parece una rosa, parece un clavel..." (Canción: La hoja, hoja verde).

Por todo lo anteriormente expuesto, se concluye que la forma de nombrar a los seres humanos en las canciones, repercute directamente en el trato dirigido hacia su persona, mostrando así desventajas de un sexo con respecto al otro.

\section{Conclusiones}

De la información recogida, se extraen una serie de conclusiones, haciendo referencia a los objetivos marcados al principio de la investigación

El primer objetivo que nos planteamos, hace referencia a la denominación de los personajes que aparecen en el texto de las canciones, y más concretamente en las tradicionales. Después del análisis de la información, se observa como existe un trato desigualitario con respecto a hombres y mujeres, pues en lo referente a su 
denominación, se denota un trato distinto entre ambos sexos. El genérico masculino se utiliza en varias ocasiones para denominar a ambos sexos, siendo ésta una forma de discriminación por omisión.

El segundo objetivo se refiere a la aportación de unas pautas de análisis del texto de las canciones, bajo una mirada de género, para descubrir si existen estereotipos en ellas. Estas pautas se han ido mencionando a lo largo de los resultados obtenidos, aunque si bien es cierto, no sólo sirven para analizar la denominación de los personajes en la letra de las canciones musicales, sino que puede servir para estudiar cualquier texto, bajo una mirada coeducativa e igualitaria.

El tercer y último objetivo marcado es que el lector o lectora del artículo, ya sea docente o no, sea capaz de reconocer que se transmiten diferentes roles según el sexo de la persona y, esto mismo, posibilite la toma de conciencia de la importancia que tiene la erradicación de las mismas, formando así personas sensibilizadas ante la relevancia de la no discriminación.

Después del análisis realizado, los datos y de los resultados obtenidos, se puede corroborar que el rol de la mujer en el texto de las canciones no está equiparado con el del hombre, conformándose con ello evidentes desigualdades entre ambos sexos. 


\section{BIBLIOGRAFÍA}

- Bardín. L. (1986): Análisis de contenidos. Madrid: Akal.

- García Gallardo, F. J. y Arredondo Pérez, H. (1995): Cancionero infantil de Huelva, Huelva: Fundación El Monte, Junta de Andalucía, Diputación de Huelva.

- L'écuyer, R. (1990) : Méthodologie de l'analyse développementale de contenu. Sillery. Presses de l'Université du Québec.

- López-Aranguren, E. (1986): “El análisis de contenido” En: M. García Ferrando, J. Ibañez y F. Alvira Martín: El análisis de la realidad social. Métodos y técnicas de investigación. Madrid: Alianza Editorial, pp. 365-396.

- Lozano Domingo, I. (1995): Lenguaje femenino lenguaje masculino. Madrid: Minerva Ediciones.

- Luis Pastor, F. (1976): La nueva canción en castellano. Madrid: Júcar.

- Machado y Álvarez, A. (1975): Demófilo. Colección de cantes flamencos. Sevilla: Ediciones Signatura.

- Manchado Torres, M. (1988): Música y mujeres: género y poder. Madrid: Horas y horas. Cuadernos inacabados.

- Maneveau, G. (1993): Música y educación. Madrid: Rialp.

- Mayer, R. y Quellet, F. (1991) : Méthodologie de recherche pour les intervenants sociaux. Boucherville: Gäetan Morin Editeur.

- Mayntz, R.; Holm, K. y Hübner, P. (1980): Introducción a los métodos de la sociología empírica. Madrid: Alianza Editorial.

- Ministerio de Educación y Ciencia (MEC) (1992): Materiales Curriculares. Educación Artística. Primaria. Madrid: Servicio de Publicaciones del MEC.

- Ministerio de Educación y Ciencia (MEC) (1992): “Transversales”. En Colección de Materiales Curriculares para la Educación Primaria: Cajas Rojas. Madrid: Servicio de Publicaciones del MEC. 
- Moreno, E. (2000): “La transmisión de modelos sexistas en la escuela”. En: M. A. Santos Guerra (coord.): El harén pedagógico. Perspectiva de género en la organización escolar. Barcelona: Graó, pp. 11-32.

- Naval, C. (1995). Educación y comunicación. Pamplona: Eunsa.

- Navarro, P. y Diaz, C. (1994): “Análisis de contenido”. En J. M. Delgado y J. Gutierrez (coods): Métodos y técnicas cualitativas de investigación en ciencias sociales. Madrid: Síntesis.

- Taylor, S. y Bogdan, R. (1985). Introducción a los métodos cualitativos de investigación. Buenos Aires: Paidós.

- Tomé, A. y Rambla, X. (eds.) (2001): Contra el sexismo. Coeducación y democracia en la escuela. Madrid: Síntesis.

- VV.AA. (1998): En femenino y en masculino. Cuaderno de educación no sexista $n^{o} 8$. Instituto de la Mujer (Seminario sobre lenguaje). Madrid 17 y 18 septiembre.

- Viñuela, L. (2003): La perspectiva de género y música popular. Dos nuevos retos para la musicología. Oviedo: KRK Ediciones.

- Willems, E. (1973): Bases psicológicas de la educación musical. Buenos Aires: Eudeba. (1976): La preparación musical de los más pequeños. Buenos Aires: Editorial Universitaria de Buenos Aires. 